\title{
Gestodene and desogestrel do not have a different influence on concentration profiles of ethinylestradiol in women taking oral contraceptives - results of isotope dilution mass spectrometry measurements
}

\author{
Lothar Siekmann, Anita Siekmann, Frank Bidlingmaier, Klaus Brill ${ }^{1}$ and Manfred Albring ${ }^{1}$ \\ Institut für Klinische Biochemie, Universität Bonn, Sigmund-Freud-Str. 25, D-53105 Bonn, Germany and ${ }^{1}$ Schering AG, Max-Dohrn-Str. 10, \\ D-10589 Berlin, Germany \\ (Correspondence should be addressed to L Siekmann)
}

\begin{abstract}
Objectives: A new method for the quantitative determination of $17 \alpha$-ethinylestradiol- $17 \beta\left(\mathrm{EE}_{2}\right)$ in serum is presented here based on the principle of isotope dilution mass spectrometry (IDMS) with $\left[{ }^{13} \mathrm{C}\right] \mathrm{EE}_{2}$ as internal standard. The technique was used to determine the concentration profiles of $\mathrm{EE}_{2}$ in the serum of female subjects who had taken oral contraceptives with different progestin components. The method has proved to be very reliable with respect to trueness, specificity, precision and detection sensitivity and offers considerable advantages compared with the immunological methods of measurement used to date.

Study design: Forty-seven female volunteers took two different oral contraceptives containing $\mathrm{EE}_{2}$ combined with different progestins in accordance with a cross-over design. After the administration of $30 \mu \mathrm{g} \mathrm{EE}_{2}$ combined with $75 \mu \mathrm{g}$ gestodene (EE2/GSD) or $150 \mu \mathrm{g}$ desogestrel (EE2/DES), blood samples were taken from the subjects on certain days and in certain previously specified cycles in the course of $12 \mathrm{~h}$ after medication.

Results and conclusions: The biometric analysis of the results showed that the concentration profiles of $\mathrm{EE}_{2}$ were, in their statistics, significantly equivalent after the administration of either of the two oral contraceptives. The sometimes contradictory results found in former studies after the administration of the different contraceptives were presumably due to the methodological shortcomings of the radioimmunological measurement technique. With the use of the highly accurate and specific technique of IDMS it can now be unequivocally established that the different progestins in the tested oral contraceptives have no influence on the bioavailability of $\mathrm{EE}_{2}$ (area under $\mathrm{EE}_{2}$ serum concentration curves, as usually defined in pharmacokinetics).
\end{abstract}

European Journal of Endocrinology 139 167-177

\section{Introduction}

$17 \alpha$-Ethinylestradiol- $17 \beta \quad\left(\mathrm{EE}_{2}\right)$ is contained as an estrogen component in all oral contraceptives used

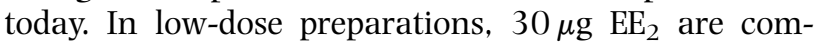
bined with $75 \mu \mathrm{g}$ gestodene (EE2/GSD) or with $150 \mu \mathrm{g}$ desogestrel (EE2/DES) as progestins. Controversy has flared up in recent years as to whether the progestin influences the metabolism of the estrogens. In particular it has been claimed that gestodene delays the metabolism of $\mathrm{EE}_{2}$ and thus leads to serum levels which are, on average, higher by $70 \%$ than those during treatment with desogestrel (1). Other well-documented clinical studies have shown, however, that, whichever progestin is used, there is no difference in the bioavailability of $\mathrm{EE}_{2}$ $(2-7)$. The controversial results have recently been discussed and reviewed (8).

The calculation of the bioavailability in these investigations is based on the measurement of the areas under the curves (AUC) of serum $\mathrm{EE}_{2}$ concentrations, which were determined in volunteer trial subjects after administration of the preparations. In all of the studies, radioimmunological measurement procedures were used to determine $\mathrm{EE}_{2}$ in the serum. It is well known, however, that immunological procedures are not very reliable, especially when, as in the present case, the concentrations to be measured in the analytical sample are very low. This is also apparent, inter alia, from the characteristics described for the immunological methods of determining $\mathrm{EE}_{2}$. A high specificity of the test procedure can be assumed when a very slight crossreactivity of the antibody used against a number of sex steroids is found, but this is contradicted by blank measurements of $\mathrm{EE}_{2}$ during the dose-free interval (6). Fluctuating $\mathrm{EE}_{2}$ blank results of up to $25 \mathrm{pg} / \mathrm{ml}$ were measured, depending on the day of the cycle. These high and fluctuating $\mathrm{EE}_{2}$ blanks are presumably caused by as yet unknown substances from the serum matrix which 
simulate $\mathrm{EE}_{2}$ during the immunological determination. This suggests that the radioimmunological test methods used probably do not provide very good accuracy and specificity. To date there have been no reports on comparative investigations using reference methods which make it possible to draw objective conclusions on the accuracy of the immunoassays used. In view of the discrepant findings in the bioavailability studies available, the question arises whether or not the value of such pharmacokinetic studies may be limited to a considerable extent, or they may even be faulty because of the unreliability of the immunological $\mathrm{EE}_{2}$ determinations.

In the study described here, therefore, a completely different principle of analysis, based on earlier investigations (9), was used to determine the serum $\mathrm{EE}_{2}$; this method - isotope dilution mass spectrometry (IDMS) is characterized by improved specificity, accuracy and precision compared with radioimmunoassay. The principle of the method was first described in 1970 (10) and it is now recognized as one of the most reliable analytical procedures in biochemical and clinical chemical analysis.

In the pharmacokinetic investigations described here, analysis by IDMS was used to determine $\mathrm{EE}_{2}$ in 47 female subjects after the administration of EE2/DES and EE2/GSD.

The purpose of the investigation was to determine whether progestins (gestodene and desogestrel) in oral contraceptives influence the pharmacokinetics of nifedipine, which was administered to the subjects simultaneously. In this connection it was of interest to find out whether the bioavailability of $\mathrm{EE}_{2}$ was equivalent after the administration of the two contraceptives. This report deals exclusively with the methodological aspects of $\mathrm{EE}_{2}$ determination by mass spectrometry and the biometric results concerning the bioavailability of $\mathrm{EE}_{2}$ after the administration of the different oral contraceptives. The biometric findings for the nifedipine kinetics will be reported elsewhere.

\section{Materials and methods}

\section{Analysis of $\mathrm{EE}_{2}$ in human serum by IDMS}

Principle of the method A measured sample of serum is mixed with a defined amount of isotope-labeled $\mathrm{EE}_{2}$ $\left(\left[{ }^{13} \mathrm{C}\right] \mathrm{EE}_{2}\right)$. The molecular structures of the labeled and the non-labeled $\mathrm{EE}_{2}$ are shown in Fig. 1. After equilibration of the labeled steroid, added exogenously, with the endogenous steroids in the serum sample, purification of the steroid fraction is carried out through extraction and column chromatography. The steroids contained in the $\mathrm{EE}_{2}$ fraction are converted into a derivative suitable for combined gas chromatography/ mass spectrometry (GCMS). The derivatives are injected into a gas chromatography column, the end of which is connected to a mass spectrometer. During the GCMS analysis a characteristic ion is continuously recorded from the spectrum of the non-labeled $\mathrm{EE}_{2}$ derivative while the corresponding ion is recorded simultaneously from the spectrum of the isotope-labeled $\mathrm{EE}_{2}$ derivative. The results are calculated from the isotope ratios determined by mass spectrometry in samples and standard mixtures of labeled and non-labeled $\mathrm{EE}_{2}$.

Measurement procedure Samples of $1.3 \mathrm{ml}$ serum taken from female subjects during the medication cycles were each mixed with $25 \mu \mathrm{l}$ of an alcoholic solution which contained $82 \mathrm{pg}\left[{ }^{13} \mathrm{C}\right] \mathrm{EE}_{2}$. A $1+9$ diluted solution of the isotope-labeled steroid $\left(8.2 \mathrm{pg}\left[{ }^{13} \mathrm{C}\right] \mathrm{EE}_{2} /\right.$ $25 \mu \mathrm{l}$ ) was used to analyze the $\mathrm{EE}_{2}$ in the serum samples taken from volunteers during the medication-free cycles (pre-period and washout cycles). The samples were shaken gently at room temperature for $30 \mathrm{~min}$ to equilibrate the labeled and non-labeled steroids. The steroids were then extracted with $15 \mathrm{ml}$ dichloromethane (Merck, Darmstadt, Germany) by vigorous shaking. The aqueous phase was siphoned off and the remaining organic phase was washed twice with $1 \mathrm{ml}$ distilled water in each case. The extract was mixed with $20 \mu \mathrm{l}$ of an alcoholic solution which contained $2 \mu \mathrm{g}$ $\alpha$-naphthol (as carrier substance). The organic solvent was evaporated to dryness under nitrogen and the dry residue was dissolved twice with $250 \mu \mathrm{l}$ of a mixture of dichloromethane, cyclohexane, methanol and water (100:80:15:1 v/v); this was then transferred to a chromatography column containing lg SephadexLH20 (Pharmacia, Freiburg, Germany). Chromatography was carried out with the same solvent mixture; $9.25 \mathrm{ml}$ of column eluate were discarded and the $\mathrm{EE}_{2}$ fraction $(1.5 \mathrm{ml})$ was then collected in conical reaction vials which contained $2 \mu \mathrm{g} \alpha$-naphthol. The precise retention volume of $\mathrm{EE}_{2}$ during Sephadex

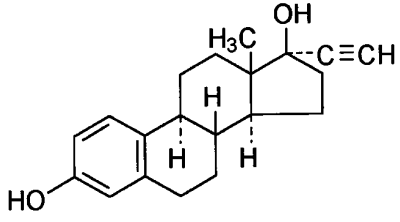

$\mathrm{EE}_{2}$<smiles>C=CC1(O)CC2C3CCC4=C(C=CC(O)C4)C3CCC21C</smiles>

$\left[3,4-{ }^{13} \mathrm{C}_{2}\right] \mathrm{EE}_{2}$
Figure 1 Molecular structure of $\mathrm{EE}_{2}$ and $\left[3,4-{ }^{13} \mathrm{C}_{2}\right] \mathrm{EE}_{2}$. 
chromatography must be determined from time to time using radioactive $\mathrm{EE}_{2}$. The developing solvent was evaporated to dryness under nitrogen and the residue was reacted with a mixture $(30 \mu \mathrm{l})$ of heptafluorobutyric anhydride and dry acetonitrile (1:4) for conversion into the heptafluorobutyric ester derivative. After a reaction time of $60 \mathrm{~min}$ at room temperature, the reagents were evaporated off in a vacuum centrifuge and dissolved in $10 \mu \mathrm{l}$ dry cyclohexane for the GCMS analysis.

For calibration, ten standards were prepared from a primary standard solution in each analytical series: four standards contained $80 \mathrm{pg}$, three standards $40 \mathrm{pg}$, and three others $120 \mathrm{pg} \mathrm{E_{2 }}$ each. The standards were pipetted into conical reaction vials, containing the same amount of isotope-labeled $\mathrm{EE}_{2}$ as had been added to the serum sample (82 pg). EE 2 (Sigma Chem. Co., Deisenhofen, Germany) (reference standard), which was dried in a vacuum before being weighed, was used as nonlabeled standard substance. The standards were converted to derivatives and dissolved under the same conditions as the analytical samples, but not subjected to column chromatography. In order to check for possible influence on quantities arising from the sample preparation procedure a duplicate of the $80 \mathrm{pg}$ standard was carried through the whole analytical procedure (extraction, chromatography, derivative formation) in each analytical series. The resulting isotope ratios did not differ by more than $1.5 \%$ from those of the non-processed $80 \mathrm{pg}$ standards.

A moving-needle solid injection system (11) was used for the injection of the samples and standards into the capillary gas chromatography column. The gas chromatography was carried out on an SE-52 column $(30 \mathrm{~m} \times 0.25 \mathrm{~mm}$, film thickness $0.1 \mu \mathrm{m}$, temperature program: start at $210^{\circ} \mathrm{C}$, temperature program $30^{\circ} \mathrm{C} /$ $\min$ to $240{ }^{\circ} \mathrm{C}, 5^{\circ} \mathrm{C} / \mathrm{min}$ to $260^{\circ} \mathrm{C}, 40{ }^{\circ} \mathrm{C} / \mathrm{min}$ to $310^{\circ} \mathrm{C}$, $2 \mathrm{~min}$ at $310^{\circ} \mathrm{C}$ ), carrier gas: helium at $80 \mathrm{kPa}$. Transfer line to mass spectrometer: deactivated fused silica capillary tube, internal diameter $0.15 \mathrm{~mm}$.

For the mass-specific detection, the quadrupole mass spectrometer (MD-800, Fisons Instruments, Mainz, Germany) connected to the gas chromatograph was adjusted to the $\mathrm{m} / \mathrm{z}$ values 474 and 476 (dwell time $50 \mathrm{~ms}$ respectively). The temperature of the ion source was $250^{\circ} \mathrm{C}$; the ionization energy was adjusted to $70 \mathrm{eV}$. The mass resolution of the instrument was focused to about 500 (10\%-valley-definition). An integrated computer system was used to control the GCMS system, to record the mass-specific chromatograms, to integrate the peak areas, to determine the peak heights and to calculate the isotope ratios.

To calculate the analysis results from the isotope ratios in the calibrator mixtures and samples, we employed a mathematical procedure which has been reported in detail (12).

Analyses were carried out in 43 batches of six to nine samples (each in duplicate). For each batch a new set of standard mixtures was prepared. For quality control a male donors' serum pool spiked with $51.2 \mathrm{pg} / \mathrm{ml} \mathrm{EE}_{2}$ was analyzed within each batch. As a limit for accepting the measurement results of a batch the maximum allowable deviation from the target value of the control sample was set to $\pm 3 \%$. The 329 serum samples were analyzed in random order. The laboratory staff were not informed of the sample codes referring to the administration of either EE2/DES or EE2/GSD.

Synthesis of $I^{\mathbf{1 3}} \boldsymbol{C} \boldsymbol{J E E _ { 2 }}$ A procedure based on a previously described method (13) was used for the synthesis of $\left[3,4-{ }^{13} \mathrm{C}_{2}\right] \mathrm{EE}_{2}$ from $2.4 \mathrm{mg}\left[3,4-{ }^{13} \mathrm{C}_{2}\right]$ estrone (Cambridge Isotope Laboratories, Woburn, MA, USA) and $16 \mathrm{mg}$ lithium acetylide in $2.5 \mathrm{ml}$ dimethylsulfoxide. After thin-layer chromatographic purification of the crude product, $0.5 \mathrm{mg}(21 \%)\left[3,4-{ }^{13} \mathrm{C}_{2}\right] \mathrm{EE}_{2}$ was obtained. The mass spectrometry analysis of this material resulted in a peak area ratio of $<0.045$ when the $\mathrm{m} / \mathrm{z}$ values 474 and 476 were recorded.

\section{Trial design for comparing $\mathrm{EE}_{2}$ bioavailability after the administration of EE2/GSD and EE2/ DES}

Volunteers A total of 74 healthy female volunteers participated in this study. Study acceptance criteria specified that the Broca index of these women should not exceed $\pm 10 \%$ and that the women should not have used oral contraceptives for at least 3 months prior to the beginning of the study. After being fully informed through written material of the purpose of the trial, each participant gave written consent. Applicants were subjected to general, gynecological and laboratory examinations including an ultrasonic examination of the liver before being selected for participation in the study. Any contraindications for oral contraceptives were regarded as exclusion criteria. All general physical examinations at the beginning of the study as well as at later time points included the following: blood samples for evaluation of nifedipine kinetics, determination of body weight and blood pressure, a standard blood glucose test, determination of the white blood cell count, a pregnancy test and a systemic drug screening. The study was conducted according to the EC guidelines of Good Clinical Practices as well as the revised declaration of Helsinki. The study was reviewed and approved by an external ethics committee (Ethikkommission der Ärztekammer Hessen, Frankfurt a. M., Germany).

Study design The study was conducted as an open intraindividual comparison following ingestion of the two preparations for 3 months each. One formulation contained $75 \mu \mathrm{g}$ gestodene in combination with $30 \mu \mathrm{g}$ $\mathrm{EE}_{2}$ (EE2/GSD) (Femovan, Schering AG, Berlin, Germany), while the second formulation contained $150 \mu \mathrm{g}$ desogestrel in combination with $30 \mu \mathrm{g} \mathrm{EE}_{2}$ (EE2/DES) (Marvelon, Organon, Oss, The Netherlands). A washout phase was 
Table 1 Experimental design for the comparison of the bioavailability of $\mathrm{EE}_{2}$ after the administration of EE2/GSD and EE2/DES.

\begin{tabular}{lcll}
\hline Cycle & Day & \multicolumn{1}{c}{ Period } & Cross-over design \\
\hline 1 & $7-12$ & Pre-period & Blank cycle \\
1 & $14-21$ & Pre-period & Blank cycle \\
2 & $14-21$ & Medication 1 & 1st treatment cycle \\
3 & - & Medication 1 & \\
4 & $14-21$ & Medication 1 & 3rd treatment cycle \\
5 & - & Washout & \\
6 & $14-21$ & Washout & Blank cycle \\
7 & $14-21$ & Medication 2 & 1st treatment cycle \\
8 & - & Medication 2 & \\
9 & $14-21$ & Medication 2 & 3rd treatment cycle \\
\hline
\end{tabular}

scheduled between the two phases of administration. The two treatment sequences were as follows (see also Table 1):

(A) EE2/GSD for a period of three cycles, washout phase for two cycles and then EE2/DES from the sixth to the eighth cycle.

(B) EE2/DES for a period of three cycles, washout phase for two cycles and then EE2/GSD from the sixth to the eighth cycle.

In order to avoid major intra-individual differences, 71 volunteers were screened in the pretreatment cycle on days 7-17 and 14-21 for nifedipine kinetics. Only volunteers with a $<20 \%$ variation in their intraindividual $\mathrm{AUC}_{\mathrm{O}-12}$ and $\mathrm{k}_{\mathrm{e}}$ (rate constant of elimination) were included in the study. Forty-seven women fulfilling the criteria were allocated at random to one of the two treatment sequences. Twenty milligrams nifedipine in non-sustained release form (Adalat, Bayer AG, Leverkusen, Germany) were administered in addition to the oral contraceptives on days 14-21 of the first and third cycles (phase A), the seventh and ninth cycles (phase B) and in the second cycle of the washout phase. Blood samples were collected via a venous outlet at $0,20,40$, $60,90,120$ and $150 \mathrm{~min}$, as well as 3, 4, 6, 8 and $12 \mathrm{~h}$ following administration on one day between the 7 th and 12 th and the 14th and 21st day of the pretreatment cycle 1. Further samples were obtained on one day between the 14th and 21st day of cycle 2 and 4 (medication 1), cycle 5 (washout period) and cycle 7 and 9 (medication 2) as shown in Table 1.

Four and $10 \mathrm{~h}$ after ingestion of the medication a standardized lunch and a second meal were given.

The statistical hypotheses to be tested by the studies are described as follows:

$$
\begin{aligned}
\mathrm{H}_{0}: & \frac{A U C_{12}(E E 2 / G S D)}{A U C_{12}(E E 2 / D E S)} \leq 0.8 \\
& \frac{A U C_{12}(E E 2 / G S D)}{A U C_{12}(E E 2 / D E S)} \geq 1.2 \\
\mathrm{H}_{1}: & 0.8 \leq \frac{A U C_{12}(E E 2 / G S D)}{A U C_{12}(E E 2 / D E S)} \leq 1.2
\end{aligned}
$$

The bioavailabilities of $\mathrm{EE}_{2}$ after administration of $\mathrm{EE} 2 /$ GSD and EE2/DES are accepted as equivalent when they do not differ by more than $20 \%$.

Preparation of weighted serum pools To determine bioavailability, the serum concentrations of the substance to be investigated are usually monitored for a certain period of time after the preparation has been taken (e.g. after 4, 12 or $24 \mathrm{~h}$ ). The AUC of the serum concentration, calculated by the trapezoidal rule, represents the measure of bioavailability. This procedure necessitates a large number of analyses, since each blood sample must be measured separately.

Recently a new procedure has been presented (14) whereby only one measurement has to be made on each investigation day to determine bioavailability: a weighted serum pool is prepared from the individual serum samples. The concentration determined in the pool multiplied by the observation period (12 h) represents a measure of the $\mathrm{AUC}_{\mathrm{O}-12}$. The individual volumes to be taken for the pool are all the greater, the longer the interval of time is before and after the blood sampling in question. Table 2 lists the individual volumes of the blood samples used to form the serum pools for the $\mathrm{EE}_{2}$ determinations; these were based on the sampling times and a target volume of $3 \mathrm{ml}$. In cases where individual blood samples were missing $(n=6$ of 4277), larger volumes were used from the blood samples taken before and after the missing sample to correspond with the longer interval of time.

A double determination was carried out from each 'weighted serum pool' using $2 \times 1.3 \mathrm{ml}$ in each case. In some cases $(n=43$ of 329$)$ the amount of serum was not sufficient for the preparation of a $3 \mathrm{ml}$ pool; then the individual volumes for the preparation of the pool were halved. Out of the resulting pool of $1.5 \mathrm{ml}$, a double determination was carried out with $0.65 \mathrm{ml}$ from each subject during the medication cycle, and single

Table 2 Production of 'weighted serum pools' for the determination of the $\mathrm{AUC}_{0-12}$

\begin{tabular}{llc}
\hline $\begin{array}{l}\text { Time after } \\
\text { administration }(\mathrm{min})\end{array}$ & $\begin{array}{c}\text { Calculation of the } \\
\text { volume }\end{array}$ & $\begin{array}{c}\text { Volume } \\
(\mathrm{ml})\end{array}$ \\
\hline 0 & $1 / 6 \times 1 / 12 \times 3=1 / 24$ & 0.042 \\
20 & $1 / 3 \times 1 / 12 \times 3=1 / 12$ & 0.083 \\
40 & $1 / 3 \times 1 / 12 \times 3=1 / 12$ & 0.083 \\
60 & $5 / 12 \times 1 / 12 \times 3=5 / 48$ & 0.104 \\
90 & $1 / 2 \times 1 / 12 \times 3=3 / 24$ & 0.125 \\
120 & $1 / 2 \times 1 / 12 \times 3=3 / 24$ & 0.125 \\
150 & $1 / 2 \times 3 / 12 \times 3=3 / 24$ & 0.125 \\
180 & $3 / 4 \times 1 / 12 \times 3=9 / 48$ & 0.188 \\
240 & $1 \times 1 / 12 \times 3=3 / 12$ & 0.250 \\
300 & $1 \times 1 / 12 \times 3=3 / 12$ & 0.250 \\
360 & $3 / 2 \times 1 / 12 \times 3=9 / 24$ & 0.375 \\
480 & $3 \times 1 / 12 \times 3=9 / 12$ & 0.750 \\
720 & $2 \times 1 / 12 \times 3=6 / 12$ & 0.500 \\
\multicolumn{2}{c}{ Total $=3.000$} \\
\hline
\end{tabular}


determinations with $1.3 \mathrm{ml}$ during the medication-free pre-period and the washout cycles.

In the case of a few pools $(n=3$ of 329$)$, the $12 \mathrm{~h}$ sample was missing or the amount of serum was too small; in these cases the samples from 0 to $480 \mathrm{~min}$ were pooled and in addition a determination was carried out on the individual samples taken at 300, 360 and $480 \mathrm{~min}$, enabling us to form an estimate on the total pool of $720 \mathrm{~min}$.

To ensure the greatest possible precision and accuracy in dosing the weighted individual volumes, adjustable piston pipettes operating with disposable tips and air cushions were calibrated gravimetrically and validated by repeated dispensing.

\section{Results}

\section{Characteristics of the analytical procedure}

Precision of the method The precision of the IDMS analysis of $\mathrm{EE}_{2}$ in serum was ascertained through double determinations carried out on 43 days on a male donors' serum pool to which $\mathrm{EE}_{2}$ had been added $(51.2 \mathrm{pg} / \mathrm{ml})$. The mean value was $51.7 \mathrm{pg} / \mathrm{ml}$. The standard deviation (s.D.) calculated from the double determinations (15), which represents a measure for the 'within series' precision, was $0.64 \mathrm{pg} / \mathrm{ml}(=1.2 \%)$. The S.D. from the 43 measurement results, as a measure of the 'series to series' precision, was calculated to be $0.80 \mathrm{pg} / \mathrm{ml}(=1.5 \%)$.

Reproducibility of the procedure was further tested by including control samples of male donors' serum pools spiked with various amounts of $\mathrm{EE}_{2}$ in four to eight analytical series. The relative S.D.s for the control pools are summarized in Table 3. The concentrations were in the range from 19 to $127 \mathrm{pg} / \mathrm{ml}$ thereby covering the concentration range of $99 \%$ of the serum samples from the treatment cycles.

The double determinations $(n=188)$ of $\mathrm{EE}_{2}$ carried out on the pools of the female subjects during the medication periods resulted in an S.D. of $0.81 \mathrm{pg} / \mathrm{ml}$. The mean concentration was $64.4 \mathrm{pg} / \mathrm{ml}$. The relative s.D. calculated from the double determinations was $1.3 \%$. This result confirms the 'within series' precision from

Table 3 Reproducibility of $\mathrm{EE}_{2}$ measurements determined after its addition to a male serum pool in different analytical series.

\begin{tabular}{lcrcc}
\hline $\begin{array}{c}\text { Added EE } \\
(\mathrm{pg} / \mathrm{ml})\end{array}$ & $\begin{array}{c}\text { Found EE } \\
(\mathrm{pg} / \mathrm{ml})\end{array}$ & $\boldsymbol{n}$ & $\begin{array}{c}\text { Relative s.D. } \\
(\%)\end{array}$ & $\begin{array}{c}\text { Recovery of }_{\mathbf{E E}_{2}} \\
(\%)\end{array}$ \\
\hline 18.63 & 19.40 & 5 & 2.2 & 104.2 \\
38.03 & 38.52 & 5 & 1.9 & 101.3 \\
51.20 & 51.70 & 43 & 1.5 & 101.0 \\
58.33 & 59.06 & 4 & 0.8 & 101.3 \\
75.89 & 77.50 & 6 & 1.1 & 102.1 \\
125.94 & 127.34 & 8 & 1.2 & 101.1 \\
\hline
\end{tabular}

double determinations on a male donors' pool to which $51.2 \mathrm{pg} / \mathrm{ml} \mathrm{EE}_{2}$ had been added.

Lower detection limit Blank value measurements on a serum pool from male donors carried out on ten different days resulted in a mean measurement value of $0.390 \mathrm{pg} / \mathrm{ml}$ (s.D. $0.145 \mathrm{pg} / \mathrm{ml}$ ). Taking into account the fact that double determinations were carried out on the subjects' sera, the following was obtained as the lower detection limit:

$$
x=x(\min ) * \frac{3 * S . D .}{\sqrt{2}}=0.699 \mathrm{pg} / \mathrm{ml}
$$

Although the samples from the premedication and washout cycles do not represent real blanks it should be noted here that their results are of similar magnitude; the double determinations $(n=120)$ of $\mathrm{EE}_{2}$ carried out on these pools resulted in a mean concentration of $0.80 \mathrm{pg} / \mathrm{ml}$ (S.D. $0.33 \mathrm{pg} / \mathrm{ml}$ ).

Lower limit of quantitation This was estimated from the data obtained in the reproducibility experiments (Table 3). It is reasonable to assume that the lower limit of quantitation (relative s.D. not exceeding 20\%) is approximately $3 \mathrm{pg} / \mathrm{ml}$.

Upper detection limit A reduced precision of the analytical results must be expected when the serum sample contains more than $160 \mathrm{pg} \mathrm{EE}_{2}$ and only $82 \mathrm{pg}$ internal standard. In this case the analysis should be repeated with a correspondingly smaller amount of serum. Otherwise there are no restrictions on the upper measurement range.

Recovery The recovery was calculated from the five serum pools to which defined amounts of $\mathrm{EE}_{2}$ had been added and which were also used for testing reproducibility. Table 3 shows the concentrations measured in different analytical series compared with the target concentrations. In the five different concentration ranges between 19 and $127 \mathrm{pg} / \mathrm{ml}$, the relative recoveries were between 101.0 and $104.2 \%$.

\section{Bioavailability of $\mathrm{EE}_{2}$ after the administration of EE2/GSD and EE2/DES}

The $\mathrm{EE}_{2}$ concentrations in 188 weighted serum pools obtained from female subjects during the medication cycles and in 141 pools from the pre-periods and washout cycles were determined through a double determination by means of IDMS analysis. The laboratory measuring the $\mathrm{EE}_{2}$ did not know whether the samples came from the EE2/GSD or EE2/DES medication cycles. The results of 1 of the 47 female subjects had to be excluded because the $\mathrm{EE}_{2}$ measurements showed that on one day she had apparently not taken the EE2/GSD preparation at the planned time. 
Table 4 Characteristic data for the $\mathrm{EE}_{2} \mathrm{AUC}_{0-12}(\mathrm{pg} \times \mathrm{h} / \mathrm{ml})$ after the administration of EE2/GSD and EE2/DES.

\begin{tabular}{|c|c|c|c|c|c|c|c|}
\hline Sequence & Cycle & Medication & Minimum & Maximum & Median & $\begin{array}{l}\text { Mean } \\
\text { value }\end{array}$ & S.D. \\
\hline \multirow[t]{2}{*}{ EE2/GSD-EE2/DES $(n=20)$} & $\begin{array}{l}1 \\
2 \\
4\end{array}$ & $\begin{array}{l}\text { EE2/GSD } \\
\text { EE2/GSD }\end{array}$ & $\begin{array}{r}3.7 \\
342.5 \\
105.2\end{array}$ & $\begin{array}{r}242.7 \\
1304.2 \\
1325.8\end{array}$ & $\begin{array}{r}10.0 \\
774.9 \\
819.7\end{array}$ & $\begin{array}{r}23.5 \\
755.0 \\
771.5\end{array}$ & $\begin{array}{r}52.2 \\
237.9 \\
303.4\end{array}$ \\
\hline & $\begin{array}{l}6 \\
7 \\
9\end{array}$ & $\begin{array}{l}\text { EE2/DES } \\
\text { EE2/DES }\end{array}$ & $\begin{array}{r}2.3 \\
173.0 \\
101.9\end{array}$ & $\begin{array}{r}19.9 \\
1380.2 \\
1430.9\end{array}$ & $\begin{array}{r}8.9 \\
809.7 \\
857.7\end{array}$ & $\begin{array}{r}9.2 \\
805.0 \\
796.9\end{array}$ & $\begin{array}{r}5.1 \\
294.7 \\
305.2\end{array}$ \\
\hline \multirow[t]{2}{*}{ EE2/DES-EE2/GSD $(n=26)$} & $\begin{array}{l}1 \\
2 \\
4\end{array}$ & $\begin{array}{l}\text { EE2/DES } \\
\text { EE2/DES }\end{array}$ & $\begin{array}{r}2.4 \\
256.9 \\
243.6\end{array}$ & $\begin{array}{r}28.0 \\
1344.2 \\
1431.7\end{array}$ & $\begin{array}{r}7.5 \\
662.9 \\
763.4\end{array}$ & $\begin{array}{r}8.8 \\
728.3 \\
840.7\end{array}$ & $\begin{array}{r}5.4 \\
263.1 \\
293.4\end{array}$ \\
\hline & $\begin{array}{l}6 \\
7 \\
9\end{array}$ & $\begin{array}{l}\text { EE2/GSD } \\
\text { EE2/GSD }\end{array}$ & $\begin{array}{r}0.8 \\
364.1 \\
108.9\end{array}$ & $\begin{array}{r}39.4 \\
1400.5 \\
1428.4\end{array}$ & $\begin{array}{r}6.6 \\
738.1 \\
736.5\end{array}$ & $\begin{array}{r}9.3 \\
770.9 \\
774.2\end{array}$ & $\begin{array}{r}8.9 \\
270.9 \\
273.4\end{array}$ \\
\hline
\end{tabular}

The results of the cross-over study are shown in Table 4. Figure 2 shows the results of the female subjects ( $n=20)$ who took EE2/GSD first (second to fourth cycle) followed by EE2/DES (seventh to ninth cycle) and of those $(n=26)$ who took the medication in the reverse sequence.

If one looks at the results of the blank cycles (first and sixth cycle), no statistically significant differences can be seen between the AUCs before EE2/GSD and before EE2/ DES. There is a tendency towards a higher value in cycle 1 compared with cycle 2 , which may be caused by the obviously outlying maximum value $(242.7 \mathrm{pg} \times \mathrm{h} / \mathrm{ml})$. But this would probably not affect the overall result of considerably higher $\mathrm{EE}_{2}$ levels after EE2/GSD and EE2/ DES.

Table 4 and Fig. 2 show that the sequence of the medication causes no significant difference in the AUCs during the treatment periods 2, 4, 7 and 9. It is therefore permissible, for the purpose of descriptive statistics, to combine the results of the treatment periods in which the contraceptive formulas were taken in the sequence EE2/GSD-EE2/DES with the treatment periods where the contraceptives were taken in the reverse order. This is shown in Table 5.

The changes seen in the third compared with the first treatment cycle (cycle 4 versus 2 and cycle 9 versus 7 ) are not statistically significant (EE2/GSD: $P=0.658$; EE2/DES: $P=0.406$ )

Figure 3 shows the AUCs determined for each female subject taking EE2/GSD compared with the AUCs of those taking EE2/DES (mean values from the first and third treatment cycle in each case). The equivalence of the bioavailability, already recognizable from the graphs, was confirmed by a statistical equivalence test,

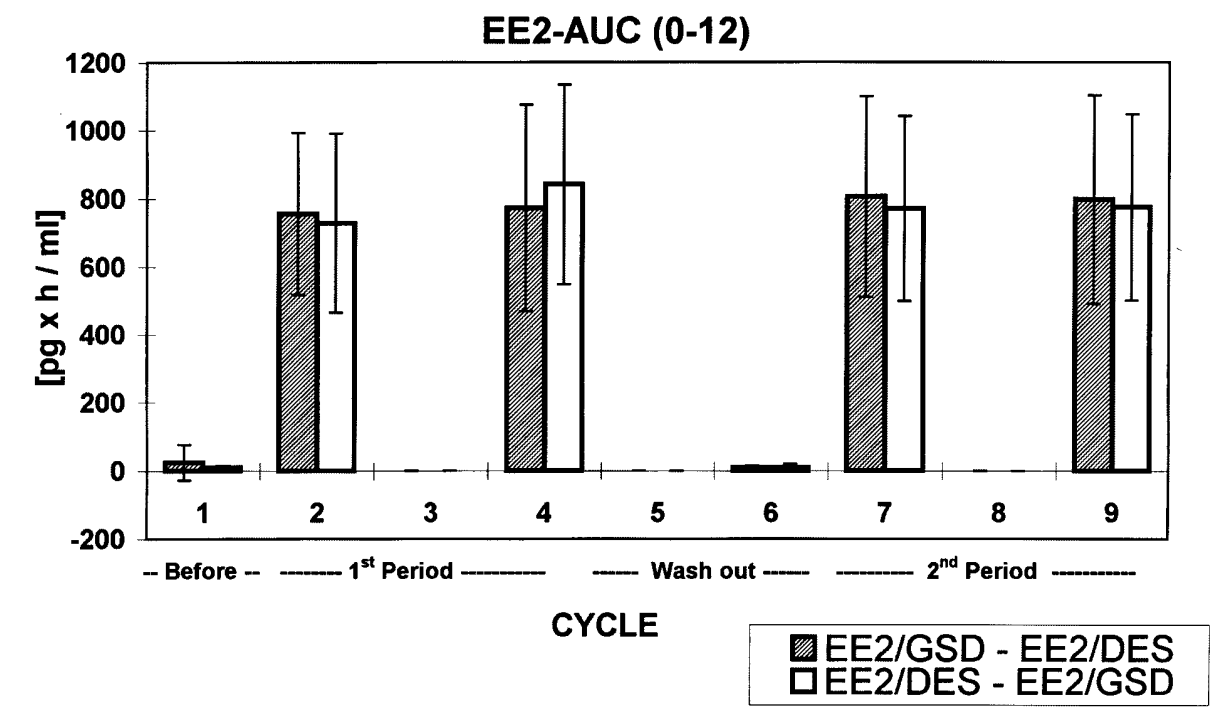

Figure 2 Mean values and S.D.s of the EE2 $\mathrm{AUC}_{0-12}$ during the medication periods and during the medication-free pre-periods and washout cycles. The female subjects $(n=20)$ who received the oral contraceptives in the first and second treatment periods in the sequence EE2/ GSD-EE2/DES and the group of subjects $(n=26)$ who received EE2/DES first and then EE2/GSD are shown separately. 
Table 5 Characteristic data for the $\mathrm{EE}_{2} \mathrm{AUC}_{0-12}(\mathrm{pg} \times \mathrm{h} / \mathrm{ml})$ after the administration of EE2/GSD and EE2/DES using the combined results from different treatment sequences.

\begin{tabular}{lcclll}
\hline & \multicolumn{2}{c}{ EE2/GSD } & & \multicolumn{2}{c}{ EE2/DES } \\
\cline { 2 - 3 } Cycle & Mean & s.D. & & Mean & S.D. \\
\hline $\begin{array}{l}\text { 1. Treatment cycle } \\
\text { (cycle 2 and 7) }\end{array}$ & 764.0 & 254.4 & & 761.6 & 276.8 \\
$\begin{array}{l}\text { 2. Treatment cycle } \\
\text { (cycle 4 and 9) }\end{array}$ & 773.0 & 283.5 & & 821.7 & 296.0 \\
\hline
\end{tabular}

which was carried out using the confidence interval inclusion method with an equivalence range of $0.8-$ 1.25 in the multiplicative model:

Equivalence test $(n=46)$

Treatment cycle 1 (cycles 2 and 7): $P=0.0031$

Treatment cycle 3 (cycles 4 and 9): $P=0.0193$

Global (mean value from all treatment cycles): $P<0.0001$

Table 6 shows the relative bioavailability of $\mathrm{EE}_{2}$ after administration of EE2/GSD versus EE2/DES, as well as the $90 \%$ confidence intervals. In the first and third treatment cycle, the relative bioavailability is 101.8 and 93.3\%. The global relative bioavailability of $\mathrm{EE}_{2}$ (after administration of EE2/GSD versus EE2/DES) for all treatment cycles is $97.5 \%$ with a $90 \%$ confidence interval between 89.5 and $106.0 \%$.

\section{Discussion}

The primary objective of this investigation was to develop a method for determining $\mathrm{EE}_{2}$ in human
Table 6 Relative bioavailability of $\mathrm{EE}_{2}$ after administration of EE2/ GSD versus EE2/DES.

\begin{tabular}{lccr}
\hline $\begin{array}{l}\text { Treatment } \\
\text { cycle }\end{array}$ & $\begin{array}{c}\text { Bioavailability } \\
(\%)\end{array}$ & $\begin{array}{c}\text { 90\% confidence } \\
\text { interval } \\
(\%)\end{array}$ & $\boldsymbol{P}$ value* \\
\hline 1 & 101.8 & $90.2-115.0$ & 0.0031 \\
3 & 93.3 & $82.6-105.3$ & 0.0193 \\
Global & 97.5 & $89.6-106.0$ & 0.0001 \\
\hline${ }^{*}$ Test of equivalence with the equivalence range $80-125 \%$.
\end{tabular}

serum that would be distinctly more reliable than the immunological procedures described to date. By using radioimmunoassay procedures one clinical study (1) produced results which were contradictory to several other investigations $(2-7)$ regarding the pharmacokinetics of $\mathrm{EE}_{2}$ after the combination of this estrogen with different progestins. Methodological factors must presumably be considered as the possible cause of contradictory results from different studies. A possible source for the discrepant results of the first study may be a systematic error as discussed recently (8); the authors of the study (1) did not analyze the samples from the two groups (EE2/DES and EE2/GSD) in random order but at different occasions in separate batches for each group. The radioimmunoassay applied in this study possibly had insufficient stability to furnish reproducible results from day to day and from batch to batch. Therefore, the difference observed by the authors of the study (1) may have been caused by the fact that the samples were not analyzed in random order and the immunoassay reproducibility was poor.

It is generally known that radioimmunological procedures are not particularly reliable, especially

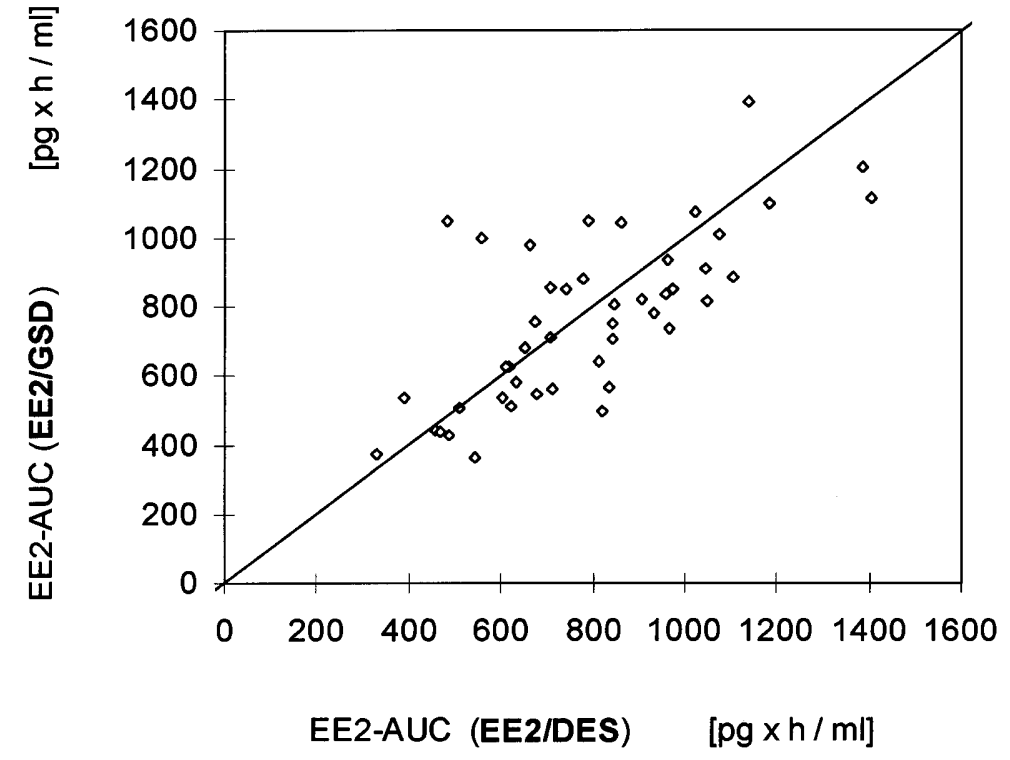

Figure 3 Presentation of the $\mathrm{EE}_{2} \mathrm{AUC}_{0-12}$ with the use of EE2/GSD versus the $E_{2} A U_{0-12}$ with the use of EE2/DES (mean values from the first and third treatment cycle). 
when dealing with concentration determinations in the femtomole range.

There is no question that the validity of pharmacokinetic equivalence investigations depends to a large extent upon the reliability of the analytical procedure used. In the field of clinical chemical laboratory diagnosis and in clinical endocrinology, the technique of IDMS is today regarded as the method of choice for developing reference measurement procedures $(12,16-$ 18). The logical assumption therefore is that, despite the high cost in terms of personnel and equipment, this analytical principle should also be used for pharmacokinetic investigations, especially if there are doubts about the reliability of alternative methods.

The accuracy of the IDMS method used here results from combining two analytical procedures: capillary gas chromatography and mass spectrometry, each of which possesses a high specificity in itself. The mass spectrometer is adjusted to the ions characteristic for the substance to be investigated thus providing a detection system whose specificity can be adapted to the measurement problem in question. In the present instance the mass spectrometer was set to the ions $\mathrm{m} / \mathrm{z}$ 474 and 476 , characteristic for the derivative of $\mathrm{EE}_{2}$ and to the corresponding isotope-labeled reference compound. Thus, only those components that form the specified ions in the mass spectrometer are selectively indicated during the gas chromatographic analysis. Figure $4 a$ and $b$ show the mass-specific detection of $\mathrm{EE}_{2}$ and $\left[{ }^{13} \mathrm{C}\right] \mathrm{EE}_{2}$ after processing a serum sample. Although the analytical sample still contains hundreds of impurities from the biological material (even after extraction and separation by column chromatography), only very few are indicated during the gas chromatography because of the mass-specific detection. $\mathrm{EE}_{2}$ can be unequivocally identified amongst these impurities by means of the characteristic gas chromatographic retention time. Not only is the specificity of the detection of great importance for analytical accuracy but also the precise control of the preparation losses during the analytical procedure. This analytical method gives optimum control of the recovery due to the use of the isotope dilution principle.

Radioimmunological measurement procedures for the determination of $\mathrm{EE}_{2}$ have been evaluated using a GCMS method (19). Although the procedure is not described in detail in that paper, it is obvious that this is not an isotope dilution analysis. In view of the absence of recovery control, it is not surprising, therefore, that the $10 \%$ coefficient of variation of the GCMS method and the lower detection limit of $10 \mathrm{pg} / \mathrm{ml}$ are hardly an improvement on the use of immunological test procedures. The fact that, in comparative investigations, the $\mathrm{EE}_{2}$ concentrations found in the relevant range up to $150 \mathrm{pg} / \mathrm{ml}$ were always higher than the radioimmunological measurements is not exactly an argument in favor of the reliability of the GCMS method used. It is questionable whether a simple GCMS method without the use of an isotope-labeled internal standard is suitable for the evaluation of immunological measurement techniques.

The descriptions of the immunological methods used to date for determining $\mathrm{EE}_{2}$ hardly provide useful information on accuracy. Statements made about accuracy are, in fact, often about the results of recovery experiments. To date no comparative analyses are available with reference methods that could provide data on the accuracy of the immunological $\mathrm{EE}_{2}$ determination procedure. The high blank values of up to $25 \mathrm{pg} / \mathrm{ml}$ determined in the medication-free intervals and reported in all the relevant publications suggest, however, that the accuracy of the immunological tests is not very high. In the case of these so-called 'blanks' one is probably dealing here with the effect of interfering substances which simulate $\mathrm{EE}_{2}$ because of the lack of specificity of the antigen/antibody reaction. It has been shown that the blank values found can be extremely variable (6). These authors quite rightly ask whether the serum blank values should be subtracted from the measurement values as was done in previous investigations (1). It is conceivable, however, that the concentration of interfering substances is altered by the influence of oral contraceptives.

The lower detection limits for the immunological determination procedures used to date are between $8 \mathrm{pg} / \mathrm{ml} \mathrm{(5)} \mathrm{and} 25 \mathrm{pg} / \mathrm{ml}$ (6). A mean serum concentration of $64 \mathrm{pg} / \mathrm{ml}$ means that a large proportion of the measurements was in fact carried out only just above the lower detection limit. With the mass spectrometry procedure used in our study, a lower detection limit of only $0.7 \mathrm{pg} / \mathrm{ml}$ was determined with the use of a pool from male donors. From determinations for the female subjects during the pre-periods and washout cycles, the detection limit was calculated at $1.5 \mathrm{pg} / \mathrm{ml}$. This considerably improved lower detection limit, compared with immunological methods, is an important prerequisite for the reliability of the IDMS method.

The question, however, arises, why different blank values were found in the serum pool of men $(0.39 \mathrm{pg} / \mathrm{ml})$ and in the medication-free and washout sera of women $(0.8 \mathrm{pg} / \mathrm{ml})$. The cause for the blanks in the IDMS method could, on the one hand, be electronic noise dependent on the technical performance of the instrument and, on the other, 'chemical' noise. And indeed it was found that in the 'blank value samples' spiked with only $8.2 \mathrm{pg}\left[{ }^{13} \mathrm{C}\right] \mathrm{EE}_{2}$, other additional substances with comparable intensity become visible, which produce signals in the selected ion chromatograms at the masses 474 and 476. These differ, however, in their gas chromatographic retention time from the derivatives of the $\mathrm{EE}_{2}$ and the ${ }^{13} \mathrm{C}$-labeled compound. However, it cannot be completely ruled out that one or more substances exhibit the same retention time as $\mathrm{EE}_{2}$ and therefore interfere with its detection. Possibly there are higher concentrations of such interfering substances in the serum of women than in that of men, which leads to 
(a)

Sample ID: $8 /$ pool

ASI16 Sm (SG, 2x2)

100

100

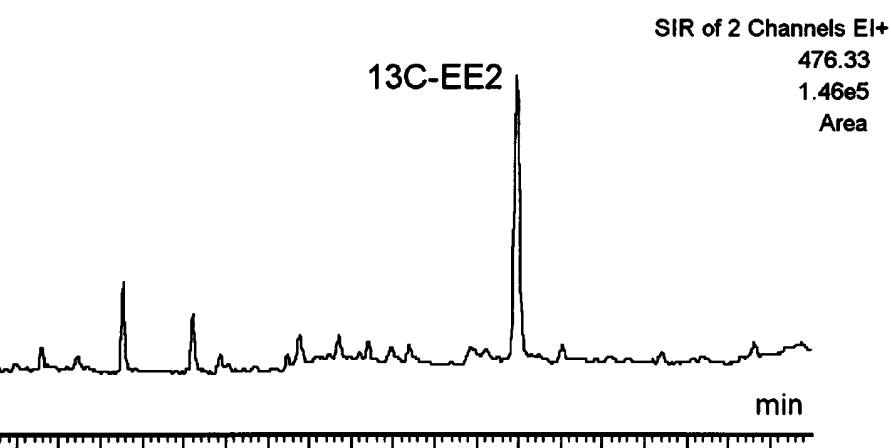

ASI16 Sm (SG, 2X2)

SIR of 2 Channels El+

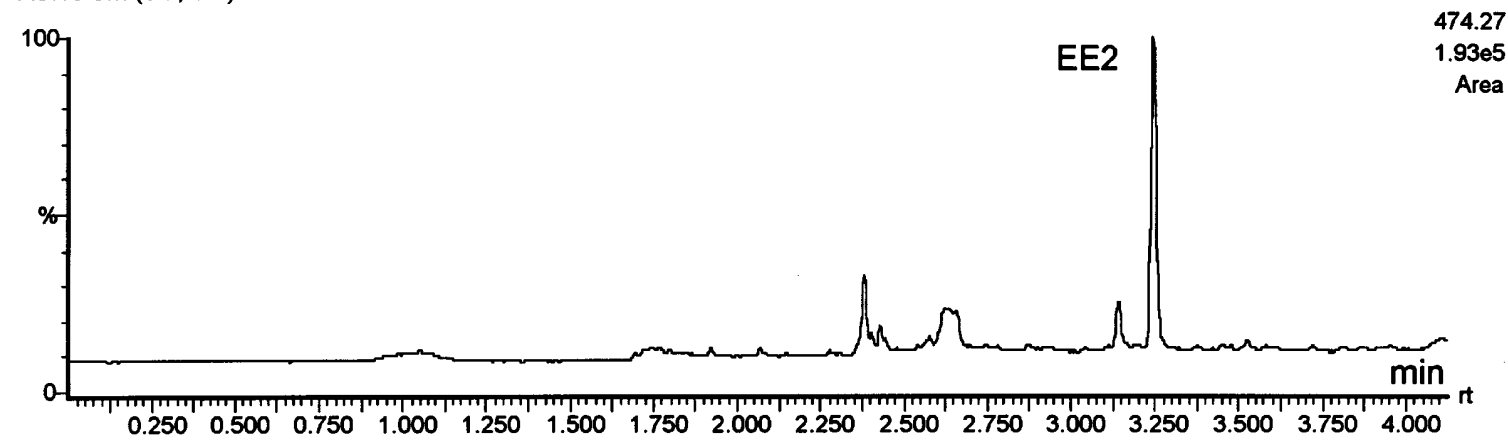

(b)

Sample ID: $8 /$ pool

ASI16 Sm (SG, 2x3)

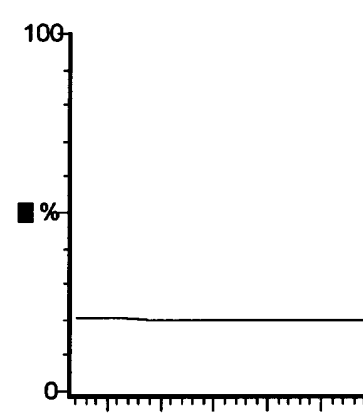

SIR of 2 Channels El+

476.33

$1.44 \mathrm{e} 5$

13C-EE2

Area

ASI16 Sm (SG, 2×3)

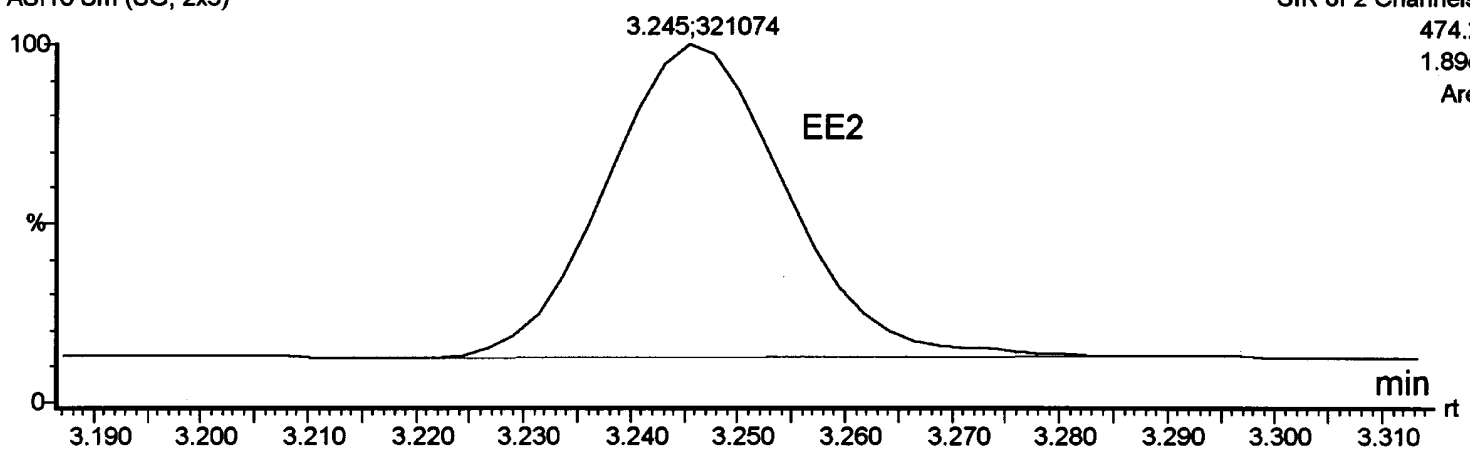

Figure 4 (a) Isotope dilution mass spectrometry analysis of the heptafluorobutyric ester derivative of $\mathrm{EE}_{2}$ after processing a serum sample. Upper chromatogram, recording of $\left[{ }^{13} \mathrm{C} \mathrm{EE}_{2}\right.$ at $\mathrm{m} / \mathrm{z} 476$; lower chromatogram, recording of the non-labeled $\mathrm{EE}_{2}$ at $\mathrm{m} / \mathrm{z}$ 474. (b) Enlarged section of the $\mathrm{EE}_{2}$ peak from the mass-specific chromatograms shown in (a). SIR, selected ion recordings. 


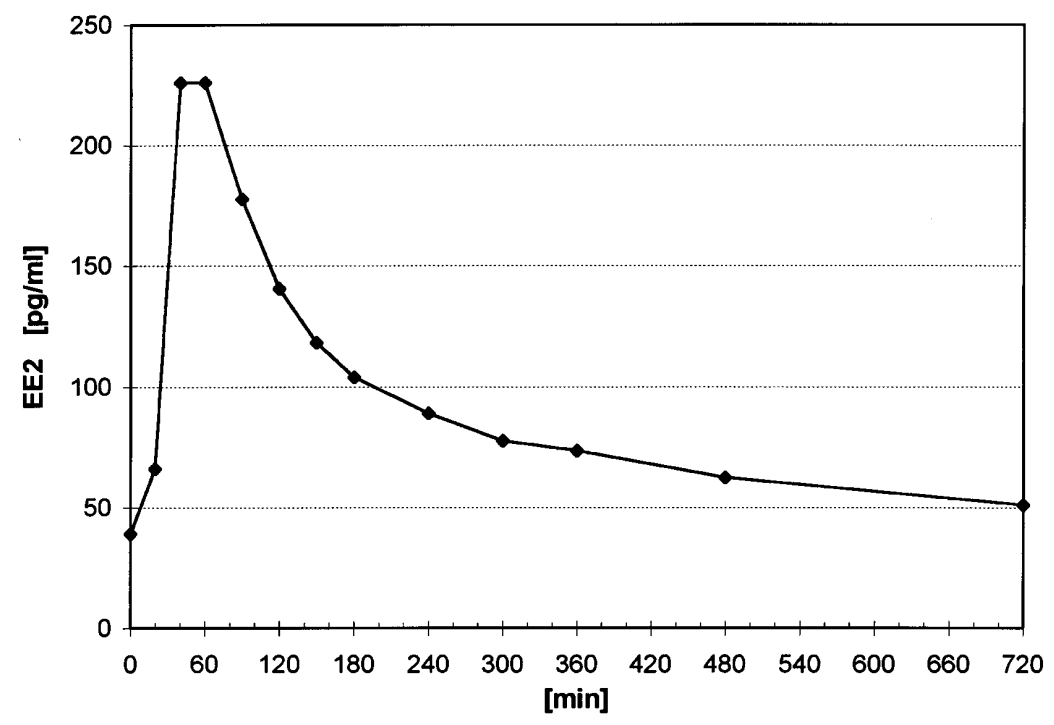

Figure $5 \mathrm{EE}_{2}$ serum concentration curve after the oral administration of $30 \mu \mathrm{g} \mathrm{EE}_{2}$ and $75 \mu \mathrm{g}$ gestodene (EE2/GSD). an increase in the lower limit of detection. The blank measurements and the phenomenon of different blanks for men and women make the limits of this methodology very clear. With reference to the evaluation of bioavailability within the framework of the present study, however, this phenomenon of blank values of about $0.8 \mathrm{pg} / \mathrm{ml}$ is quantitatively insignificant.

The precision calculated from repeated 'series to series' measurements is a parameter of reliability reported in all of the available studies that use an immunological measurement technique. Thus a coefficient of variation from 'series to series' of $15.1 \%$ (with a mean concentration of $70 \mathrm{pg} / \mathrm{ml}$ ) was reported (1). This roughly corresponds to the data of another paper reporting a 'series to series' coefficient of variation of $16.0 \%$ with a mean concentration of $48.7 \mathrm{pg} / \mathrm{ml}$ (6). With an $\mathrm{EE}_{2}$ concentration of $143 \mathrm{pg} / \mathrm{ml}$, the coefficient of variation lies at $9.4 \%$. In a recent paper (7) 'series to series' coefficients of variation of $13.3 \%$ are reported at a concentration of $93.2 \mathrm{pg} / \mathrm{ml}$ and of $12.6 \%$ at $192.2 \mathrm{pg} / \mathrm{ml}$. By comparison with the immunological procedures, the IDMS method described here has proved to be very precise. The coefficient of variation was generally about $1.2 \%$ 'within series' and approximately $1.5 \%$ 'series to series'.

It is reported (14) that, with the weighted pools method used here, the variance of the bioavailability determination increases in a ratio of $2.625 \times \mathrm{s}^{2}$ to $18.625 \times \mathrm{s}^{2}$, i.e. by a factor of 7.1 compared with the trapezoidal method. If, however, one looks at the scatters of $\mathrm{s}^{2}$, which are on an order of magnitude of 100 with immunological methods compared with 0.97 with IDMS, then the contributions to the individual variances are: $2.652 \times 100=265$ for the trapezoidal method with immunological procedures and $18.625 \times$ $0.97=18.1$ for the 'weighted pools' method using mass spectrometry.

This results in a distinct advantage for the use of IDMS determination, even though the preconditions are less good through the weighted pools method. In order to compare the 'weighted pools' method with the usual 'trapezoidal method' from $\mathrm{EE}_{2}$ serum concentration curves, individual measurements in the course of $12 \mathrm{~h}$ and also a 'weighted pool' of the 13 individual samples were carried out for the 1 day measurement of four subjects. Figure 5 shows a typical $\mathrm{EE}_{2}$ serum concentration curve, such as was obtained with the use of the IDMS analysis for one female subject. Table 7 shows the results of the 1 day measurements of four subjects as a comparison. There is a good correlation between the two methods, so that no reservations should exist as to the use of 'weighted pools', as already reported (14).

Taken as a whole, the IDMS analysis of the serum $\mathrm{EE}_{2}$

Table 7 Comparison of the $\mathrm{EE}_{2} \mathrm{AUC}_{0-12}(\mathrm{pg} \times \mathrm{h} / \mathrm{ml})$ determined from 13 individual measurements by the 'trapezoidal method' and from a concentration measurement in the 'weighted serum pool'.

\begin{tabular}{lcccc}
\hline Subject & $\begin{array}{c}\text { Weighted pool } \\
\text { AUC }_{\mathbf{0 - 1 2}}\end{array}$ & $\begin{array}{c}\text { Trapezoidal method } \\
\text { AUC }_{\mathbf{0 - 1 2}}\end{array}$ & $\begin{array}{c}\text { Difference in } \\
\text { AUC }_{\mathbf{0 - 1 2}}\end{array}$ & $\begin{array}{c}\text { Relative difference } \\
(\%)\end{array}$ \\
\hline 011 & 992.2 & 1008.5 & -16.3 & -1.6 \\
249 & 1030.2 & 1059.7 & -29.5 & -2.8 \\
265 & 990.6 & 959.4 & 31.2 & +3.3 \\
270 & 1154.0 & 1164.7 & -10.7 & -0.9 \\
\hline
\end{tabular}


described here must be seen as a quantitative analytical procedure which is distinctly superior to the immunological methods in specificity, trueness, precision and lower limit of quantitation. The use of the method described here for determining $\mathrm{EE}_{2}$ in a cross-over study that administered nifedipine as well as $\mathrm{EE}_{2}$ and the different progestins did not afford any evidence that the bioavailability of $\mathrm{EE}_{2}$ differs at all after the administration of either EE2/GSD or EE2/DES. The possibility that the progestins (gestodene and desogestrel) might have differing effects on the metabolism of $\mathrm{EE}_{2}$ can therefore be excluded.

\section{Acknowledgements}

The authors would like to thank Dr H J Wildgrube, Institute for Applied Diagnostics, D-63450 Hanau for collecting the blood samples for $\mathrm{EE}_{2}$ analyses. We also wish to thank Mrs Anja Schumacher for the careful synthesis of the $\left[{ }^{13} \mathrm{C}\right] \mathrm{EE}_{2}$.

\section{References}

1 Jung-Hoffmann C \& Kuhl H. Interaction with the pharmacokinetics of ethinylestradiol and progestogens in oral contraceptives. Contraception 198940 299-312.

2 Hümpel W, Täuber U, Kuhnz W, Pfeffer M, Brill K, Heithecker R et al. Comparison of serum ethinyl estradiol, sex-hormonebinding globulin, corticoid-binding globulin and cortisol levels in women using two low-dose combined oral contraceptives. Hormone Research 199033 35-39.

3 Kuhnz W, Hümpel M, Schütt B, Louton T, Steinberg B \& Gansau C. Relative bioavailability of ethinyl estradiol from two different oral contraceptive formulations after single oral administration to 18 women in an intraindividual cross-over design. Hormone Research 199033 40-44.

4 Kuhnz W, Back D, Power J, Schütt B \& Louton T. Concentration of ethinyl estradiol in the serum of 31 young women following a treatment period of three months with two low-dose oral contraceptives in an intraindividual cross-over design. Hormone Research 199136 63-69.

5 Orme M, Back DJ, Ward S \& Green S. The pharmacokinetics of ethinylestradiol in the presence and absence of gestodene and desogestrel. Contraception 199143 305-316.

6 Dibbelt L, Knuppen R, Jütting G, Heimann S, Klipping CO \& Parikka-Olexik H. Group comparison of serum ethinyl estradiol, SHBG and CBG levels in 83 women using two low-dose combination oral contraceptives for three months. Contraception $1991431-21$.

7 Hammerstein J, Daume E, Simon A, Winkler HU, Schindler AE, Back DJ et al. Influence of gestodene and desogestrel as components of low-dose oral contraceptives on the pharmacokinetics of ethinyl estradiol (EE2), on serum CBG and on urinary cortisol and 6 $\beta$-hydroxycortisol. Contraception 199347 263281.

8 Stanzcyk FZ. Pharmacokinetics of the new progestogens and influence of gestodene and desogestrel on ethinylestradiol metabolism. Contraception 199755 273-282.

9 Siekmann L, Siekmann A \& Breuer H. Measurement by isotope dilution mass spectrometry of $17 \alpha$-ethynyloestradiol-17 $\beta$ and norethisterone in serum of women taking oral contraceptives. Environmental and Biomedical Mass Spectrometry 19807 511514.

10 Siekmann L, Hoppen HO \& Breuer H. Zur gaschromatographischmassenspektrometrischen Bestimmung von Steroidhormonen in Körperflüssigkeiten unter Verwendung eines Multiple Ion Detectors (Fragmentographie). Zeitschrift für Analytische Chemie 1970 252 294-298.

11 Van den Berg PM \& Cox TPH. An all-glass solid sampling device for open tubular columns in gas chromatography. Chromatographia $19725301-305$.

12 Siekmann L \& Breuer H. Determination of cortisol in human plasma by isotope dilution-mass spectrometry. Journal of Clinical Chemistry and Clinical Biochemistry $198220883-892$.

13 Rao PN. Preparation of $9 \alpha, 11 x$-tritiated $17 \alpha$-ethinylestradiol, mestranol, estradiol-17 $\beta$, and norethindrone. Steroids 197118 219-229.

14 Louton T, Kuhnz W, Dibbelt L \& Knuppen R. Weighted serum pools in comparison to the trapezoidal rule for estimating AUCs for ethinyl estradiol. The relationship of the variance of the determination to the interindividual variance. European Journal of Clinical Pharmacology 199446 77-81.

15 Snedecor GW. Query. Biometrics 19528 85-86.

16 Siekmann L, Spiegelhalder B \& Breuer H. Bestimmung von Aldosteron im Plasma des Menschen unter Verwendung der Kombination Gaschromatographie/ Massen-spektrometrie. Zeitschrift für Analytische Chemie 1972261 377-381.

17 Siekmann L. Determination of steroid hormones by the use of isotope dilution-mass spectrometry: a definitive method in clinical chemistry. Journal of Steroid Biochemistry 197911 117-123.

18 Siekmann L. Determination of oestradiol-17 $\beta$ in human plasma by isotope dilution-mass spectrometry. Journal of Clinical Chemistry and Clinical Biochemistry 198422 551-557.

19 Kuhnz W, Louton T, Back DJ \& Michaelis K. Radioimmunological analysis of ethinylestradiol in human serum. Validation of the method and comparison with a gas chromatographic/mass spectrometric assay. Arzneimittel Forschung 199343 16-21.

Received 31 December 1997

Accepted 27 April 1998 